\title{
In Vitro Comparative Efficacy of Two Techniques for Irrigant Delivery in Curved Root Canals
}

\author{
Raouf H. Helmy ${ }^{{ }^{*}} B D S$, Nayera A. Mokhless ${ }^{2} P h D$, Rania M. El Backly ${ }^{3} P h D$
}

\begin{abstract}
INTRODUCTION: One of the goals of conventional endodontic treatment is to minimize the amount of irritants that could be present inside the root canal system.

OBJECTIVES: This study was designed to evaluate irrigant delivery using two different techniques in curved canals.

MATERIALS AND METHODS: The mesiobuccal canals of 20 human extracted mandibular first molars were divided into two groups $(\mathrm{n}=10)$; Group (I) conventional syringe with side vented needle, Group (II) sonic irrigation (EndoActivator system). Contrast medium (OptirayTM 320, Mallinckrodt Inc. Hazelwood, MO, USA) was injected before, during and after canal preparation. All canals were prepared using Revo-S rotary system till reaching file AS35 using $5.25 \% \mathrm{NaOCl}$ as an irrigant during instrumentation. Standardized preoperative, operative and postoperative digital radiographs were taken. The distance between full working length and the point of maximum irrigant penetration was measured using image editing software (DBS Win 5.3.1 and Image J). Data were then recorded and statistically analyzed.

RESULTS: Sonic irrigation showed a statistical significant difference over the conventional needle and syringe group in increasing the depth of penetration of the contrast medium.

CONCLUSIONS: the use of EndoActivator in irrigation had a superior effect in increasing the depth of penetration of irrigant when compared to conventional needle and syringe.

KEYWORDS: EndoActivator, Irrigant penetration depth, conventional side vented syringe, recent irrigation technique

1- Bachelor of Dentistry, BDS, Faculty of Dentistry, Alexandria University, Alexandria, Egypt.

2- Assistant Professor of Endodontics, Conservative Dentistry Department, PhD, Faculty of Dentistry, Alexandria University, Alexandria, Egypt.

3- Lecturer of Endodontics, Conservative Dentistry Department, PhD, Faculty of Dentistry, Alexandria University, Alexandria, Egypt.
\end{abstract}

\section{INTRODUCTION}

One of the biggest challenges in endodontic irrigation is the cleaning of the apical third of the canal. To achieve cleanliness and canal debridement, an effective irrigation technique should be implemented to facilitate the penetration of the irrigating solution into the apical third of the canal without forcing it into the periapical tissues $(1,2)$. Numerous techniques have been introduced aiming to enhance the efficacy of irrigation regarding not only penetration depth of the irrigant but also its ability to effectively influence debris and smear layer removal (3).

Activating the irrigation solution is another method that results in cleaner surfaces in the root canals when compared to conventional irrigation. Based on this concept, sonics (e.g. EndoActivator System) (Dentsply, Tulsa, Ok) were introduced to activate the irrigant, thereby improving debris removal and enhancing the disinfection of the root canal $\operatorname{system}(2,4)$.

Sonically activated systems such as the EndoActivator system have been reported to increase the efficacy of irrigation and enhance disinfection $(4,5)$. This device uses a cordless sonic handpiece to activate highly flexible and strong polymer tips. These tips are non-cutting and tapered with terminal diameters that closely match the dimensions of the final canal preparation (4). The EndoActivator produces mechanical oscillations principally at the tip of the activator with a maximum frequency of 10000 Cycles per minute (cpm).

Studies on the performance of these irrigation systems and their ability to deliver irrigation to the apical part of curved canals of molars are still inconclusive. Moreover, conflicting results regarding the effectiveness of sonic activation of the irrigant to remove smear layer, debris, and bacteria have been published (6-8). The lack of conclusive results could be due to the difference in depth of penetration achieved by these systems. Hence, the objective of the current study was to use an in vitro model to evaluate the depth of penetration of the irrigant using 2 different techniques in association with a contrast medium and a modified image analysis technique.

\section{MATERIALS AND METHODS}

This study was conducted following the requirements of the Institutional Review Board (IRB) of the faculty of dentistry, Alexandria University regarding research involving human tissues. The study was undertaken as a randomized doubleblinded one.

Twenty extracted human mandibular first molars were used in the study. Mesial roots were selected such that the curvature angle was 25 degrees or more according to Schneider's technique (9). Crowns were shortened to a level that allowed the pulp chamber to be left intact and to obtain a standardized mesial root length of $17 \mathrm{~mm}$. The distal root was amputated. To obtain a closed canal system, an apical seal with wax was made. The teeth were accessed and uninvolved canal orifices were sealed. The working length (WL) was established. Teeth were positioned using a radiographic platform for standardization(10). It consisted of the following: (1) Kerr X-ray sensor holder (Howe; Kerr, Orange, CA, USA). (2) Plastic base: Fitting on the sensor holder with a hole drilled to precisely receive the protrusion found in the plastic cube and having a frontal slab with a 4.2 mm stainless steel wire to act as a constant scale (digital ruler) for the measurements.

Preoperative mesiodistal radiographs were taken using digital radiovisiography (Vistaray 7 sensor with DBS Win 5.3.1 software, Dürr Dental \& Co. KG, BietigheimBissingen, Germany). Contrast medium; Optiray TM 320 (Mallinckrodt Inc. Hazelwood, MO, USA) was injected inside the canal (In room temperature $25^{\circ} \mathrm{C}$ ) using a side- 
vented needle (Vista-Probe TM, Inter-Med, Inc., USA) which was used for all subsequent irrigation steps. In every step, the needle was placed in the canal as apical as possible. Mesiodistal radiographs were taken to confirm the depth of contrast medium penetration inside the canal before canal preparation to guide as a baseline. This first injection was termed (p1).

\section{Canal preparation and irrigation techniques}

Size 10 and $15 \mathrm{k}$-files were used to establish a glide path and the canals were prepared with rotary files; REVO-S ${ }^{\text {TM }}$ (Micro-Mega, France) to file SC2 and irrigated with $2 \mathrm{~mL}$ of $5.25 \%$ Sodium Hypochlorite $(\mathrm{NaOCl})$ between each file. Teeth were then randomly allocated to one of 2 groups. Contrast medium was then injected in the root canals (p2) of the two groups after canal preparation as follows: In Group I (conventional method): Canals were irrigated with $2 \mathrm{~mL}$ of $5.25 \% \mathrm{NaOCl}$ followed by $1 \mathrm{ml}$ of contrast medium. In Group II (Sonic irrigation with Endo activator system): Canals were irrigated with $2 \mathrm{~mL}$ of $5.25 \% \mathrm{NaOCl}$ followed by $1 \mathrm{ml}$ of contrast medium which was then sonically agitated with the polymer tip (size 25/.04) placed inside the canal as apical as possible for 30 seconds.

Following these steps for the two groups, standardized mesiodistal radiographs were obtained then root canal instrumentation was continued using REVO-S ${ }^{\mathrm{TM}}$ files SU, AS30 and AS35 followed by irrigation then final contrast medium injection (p3) as previously described for each group, respectively. Finally, mesiodistal radiographs were obtained in the same manner as before.

\section{Radiographic and image analysis}

All radiographs were anonymously labeled prior to being subjected to interpretation. The analysis of the images was done via a calibrated examiner, double blinding was performed since neither the analyst nor the statistician was aware of the assigned treatments to the various groups. The distance between the working length and maximum irrigant penetration in the two groups was measured using image editing software (DBS Win 5.3.1) and Image J software (National Institutes of Health, Bethesda, MD, USA). In every image taken; a $4.2 \mathrm{~mm}$ stainless steel wire was included to act as a constant scale (digital ruler) for the measurements.

In order to accurately distinguish between the injected contrast medium from the canal dentinal walls, Image J software was used to standardize image contrast thresholds with contrast range of (55-199) which was standardized for all samples. Images of the injected contrast medium before, during and after canal instrumentation were marked at the maximum penetration point as $\mathrm{p} 1, \mathrm{p} 2$, and $\mathrm{p} 3$, respectively, then the three images were superimposed on each other accurately using (Adobe ${ }^{\circledR}$ Photoshop ${ }^{\circledR}$ software) as shown in fig 1.The superimposition process was done by overlaying the digital radiographs in different transparent layers and analyzing the depth of penetration of the contrast medium accordingly. The measurements were then done using Image $\mathrm{J}$ software.

\section{STATISTICAL ANALYSIS}

After data was collected, revised, coded and fed to statistical software (IBM SPSS version 20). All statistical analysis was done using two tailed tests and alpha error of 0.05 . P values less than or equal to 0.05 was considered to be statistically significant.
$P$ values were adjusted for multiple pairwise comparisons to avoid inflation of type I error using the Bonferroni correction method. Analysis of numeric data was done using One-Sample Kolmogorov-Smirnov Test, One Way ANOVA and Repeated Measures ANOVA.

\section{RESULTS}

In this study, all groups showed a statistically significant difference in the depth of penetration of the contrast medium during and after instrumentation when compared to the baseline values before starting instrumentation $(p<0.05)$. The mean deepest penetration was found after instrumentation (p3) followed by the penetration during instrumentation (p2) and finally the penetration depth before instrumentation ( $\mathrm{p} 1)$ (table 1,2 and fig.1,2 and 3).

Table (1): Describes the (Minimum, Maximum,

Mean and SD) of the depth of penetration of contrast medium in $\mathrm{mm}$ in group I before (p1), during (p2) and after instrumentation (p3)

\begin{tabular}{|c|c|c|c|c|}
\hline $\begin{array}{c}\text { Conventional } \\
\text { needle and } \\
\text { syringe }\end{array}$ & $\begin{array}{c}\text { Before } \\
\text { preparat } \\
\text { ion }\end{array}$ & $\begin{array}{c}\text { During } \\
\text { preparat } \\
\text { ion }\end{array}$ & $\begin{array}{c}\text { After } \\
\text { prepara } \\
\text { tion }\end{array}$ & \multirow{2}{*}{ F (P) } \\
\hline Minimum & 8.62 & 3.13 & 0.00 & \multirow{2}{*}{39.3} \\
\hline Maximum & 12.83 & 8.73 & 5.84 & $(0.00$ \\
\hline Mean & 10.47 & 6.03 & 3.04 & \multirow{2}{*}{$1)^{*}$} \\
\hline SD & 1.57 & 2.04 & 2.01 & \\
\hline
\end{tabular}
F: Repeated measures ANOVA
* $<0.05$ (significant)

When comparing the results of the two groups, it was found that the group of EndoActivator showed a statistically significant difference $(\mathrm{p}<0.05)$ over the conventional needle and syringe group in increasing the depth of penetration of the contrast medium during and after canal instrumentation as compared to before instrumentation.

Interestingly, the depth of irrigation with the conventional needle and syringe showed a gradual increase from $\mathrm{p} 1$ to $\mathrm{p} 2$ to $\mathrm{p} 3$ while, the increase in depth of penetration of the irrigant was minimal from $\mathrm{p} 2$ to $\mathrm{p} 3$ for the EndoActivator group. It was found that the mean values of p2 for the EndoActivator group indicated that the irrigant effectively reached the final apical $1 \mathrm{~mm}$ of the preparation even before the instrumentation phase was completed where the apical diameter was equivalent to just $0.25 \mathrm{~mm}$.

Table (2): Describes the (Minimum, Maximum, Mean and SD) of the depth of penetration of contrast medium in $\mathrm{mm}$ in group II before (p1), during (p2) and after instrumentation (p3)

\begin{tabular}{|c|c|c|c|c|}
\hline $\begin{array}{c}\text { Sonic Endo- } \\
\text { Activator } \\
\text { System }\end{array}$ & $\begin{array}{c}\text { Before } \\
\text { preparat } \\
\text { ion }\end{array}$ & $\begin{array}{c}\text { During } \\
\text { preparat } \\
\text { ion }\end{array}$ & $\begin{array}{c}\text { After } \\
\text { prepara } \\
\text { tion }\end{array}$ & F (P) \\
\hline Minimum & 8.76 & 0.00 & 0.00 & \multirow{2}{*}{85.4} \\
\hline Maximum & 13.67 & 0.60 & 0.32 & $(0.001$ \\
\hline Mean & 11.31 & 0.14 & 0.06 & )$^{*}$ \\
\hline SD & 1.86 & 0.24 & 0.12 & \\
\hline
\end{tabular}

F: Repeated measures ANOVA

$* \mathrm{P}<0.05$ (significant)

\section{DISCUSSION}

A well-established fact states that increasing the depth of penetration of the irrigating solution in the root canal with 
an effective irrigation technique achieves better cleanliness and canal debridement $(1,2,11)$.

In this study, Optiray was used as a contrast medium, because it is a sterile, non-pyrogenic, aqueous, non-ionic, and water-soluble solution. It is worth mentioning that the viscosity of $5.25 \% \mathrm{NaOCl}$ stated by Guastalli et al (12) and Gopikrishna et al (13) was not identical to the viscosity of Optiray ${ }^{\text {TM }} 320$ (Ioversol) stated by Seeliger et al (14). However, since the viscosity of Optiray ${ }^{\mathrm{TM}} 320$ was higher than that of $5.25 \% \mathrm{NaOCl}$, this assumes that the penetration depth measured was not influenced by this difference and assures the potential of the irrigation techniques used to deliver the irrigant to the apex. Moreover, this contrast medium injected inside the canals "resembling the irrigating solution" proved to effectively show the proper radio opacity required to measure depth of penetration inside the root canal.
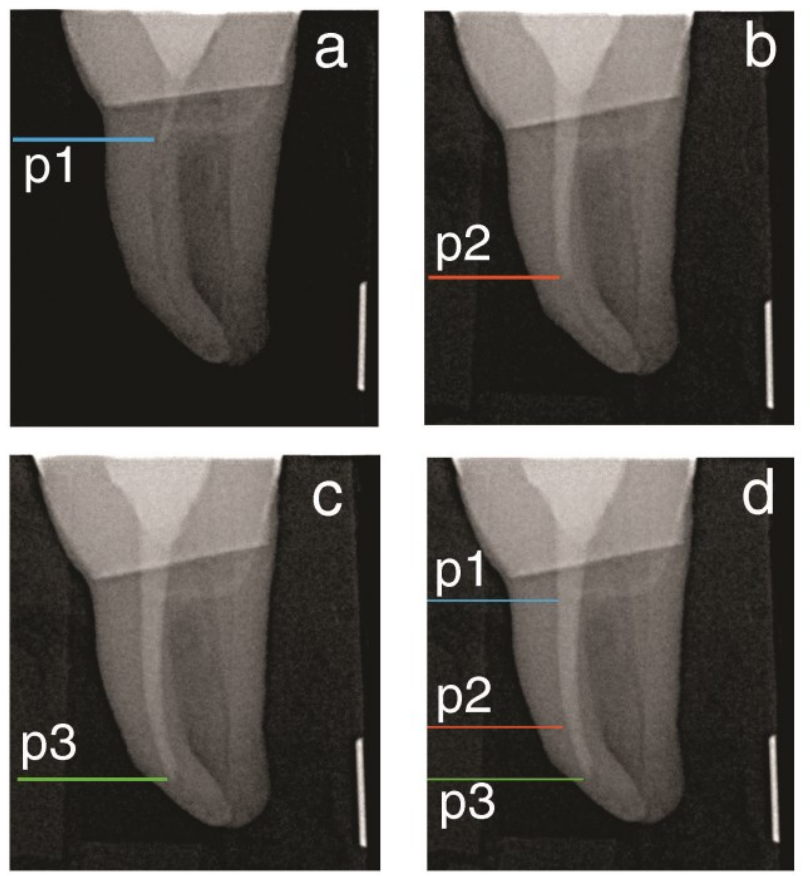

Figure (1): Method of measurement of irrigant delivery by measuring the depth of penetration of the contrast medium where (a) is the penetration depth of the contrast medium before instrumentation (p1); (b) is the penetration depth during instrumentation (p2); (c) is the penetration depth after instrumentation (p3); (d) is superimposition of images in a, b, and c showing overall penetration depth. (Images are for one representative tooth)

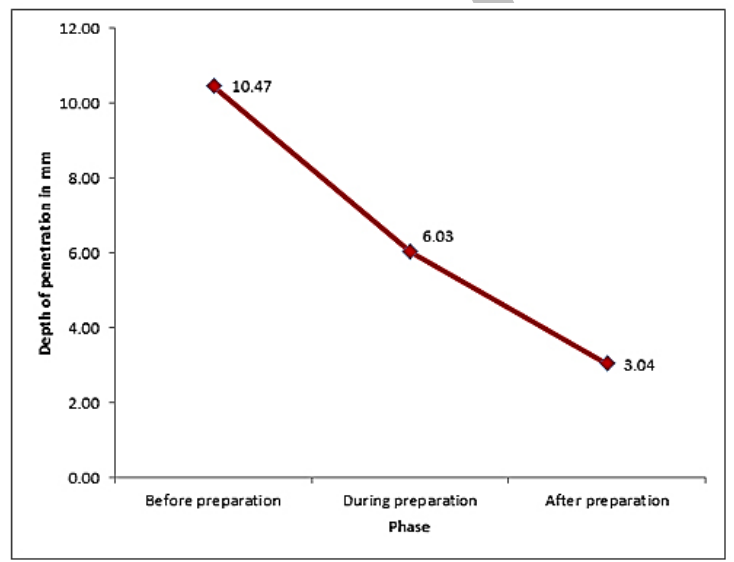

Figure (2): Graph representing the mean depth of penetration in $\mathrm{mm}$ before, during and after instrumentation in group I.

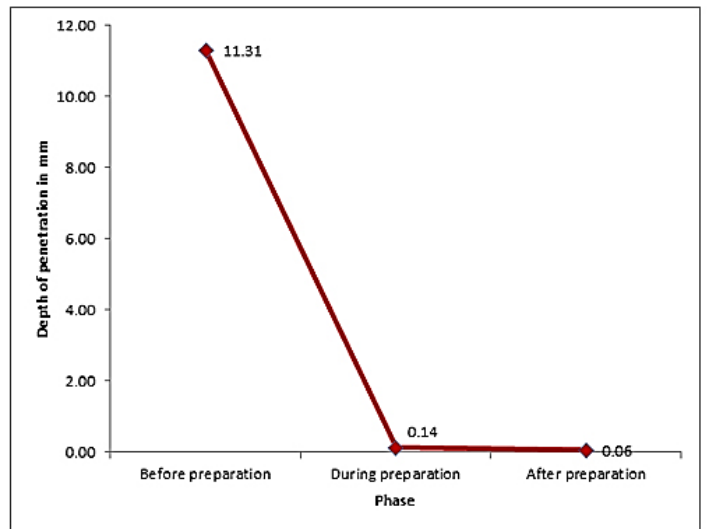

Figure (3): Graph representing the mean depth of penetration in $\mathrm{mm}$ before, during and after instrumentation in group II.

In this study we used a non-invasive technique by superimposition of digital radiographs which allowed real time evaluation of the depth of penetration of the irrigant. Such a technique can also be potentially used in a clinical setting.

Classic irrigation techniques have shown an effective disinfection of coronal and middle canal thirds with little cleaning efficacy of the apical third (15). Some authors have also shown that root canal irregularities were blocked and filled with canal debris left behind after conventional needle irrigation $(16,17)$. Indeed, in the present study the conventional endodontic needle was not able to deliver irrigating solution deep enough to the apical third even after final apical preparation to $0.35 \mathrm{~mm}$. Another factor that may account for limited irrigant penetration into the apical third with the conventional endodontic needle is the phenomenon of the "vapor lock effect" (18).

It is important to note that in this study we compared irrigant delivery not only before and after complete instrumentation but also during instrumentation emphasizing the efficacy of the sonic irrigation technique. This is also demonstrated by the fact that the irrigant could reach the apical $1 \mathrm{~mm}$ of the canal even before instrumentation was finalized in contrast to what was noted when using the conventional syringe and needle.

In terms of penetration depth of the irrigant, sonic activation technique significantly improved irrigant delivery. This could be related to the superior ability of this system in removing remnants of pulp tissue and dentin debris from root canals $(7,16,19)$. Sonic irrigation provides similar abilities at the same time reducing the chance for irrigant extrusion owing to the lower frequencies employed. Indeed, the EndoActivator has been shown to better remove the smear layer (20), but others have reported limited benefits of the EndoActivator over needle irrigation in this aspect $(3,21)$. In the literature, sonic irrigant activation did not enhance smear layer removal when compared to the conventional method without using EDTA solutions. Moreover, previous studies have demonstrated that sonic instrumentation are not better than hand instrumentation in disinfecting (22) or cleaning (23) root canals however, this was outside the scope of the present study.

It is important to note that sonic activation allowed the irrigant to circulate much deeper in the canal after canal enlargement to only size \#25. This would ensure canal debridement to create a bacteria free environment without unnecessary canal enlargement hence decreasing the risk of 
root fracture, decreasing the number of intracanal instruments used and saving time and effort for the clinician and the patient.

Although the depth of irrigant delivery was maximized in this study by the afore-mentioned technique, it remains to be seen whether or not in this same experimental model there would be differences in debris removal. The efficacy of this technique on reaching lateral and accessory canals also warrants further investigation. One further limitation of the current study is that we did not compare between the two groups regarding irrigant extrusion although it has been previously shown that irrigant extrusion appears to be less with sonic irrigation (1). The chosen analysis method was based upon two-dimensional radiography, therefore, the study lacked quantitative volumetric data and therefore the spreading pattern of the Optiray contrast material inside the canals may not exactly match that of $5.25 \% \mathrm{NaOCl}$. Other variables were standardized in the current study such as the size of apical canal preparation so as not to affect the results.

\section{CONCLUSIONS}

The use of EndoActivator in irrigation had a superior effect in increasing the depth of penetration of the irrigating solution when compared to a conventional needle and syringe.

\section{CONFLICT OF INTEREST}

The authors declare that they have no conflicts of interest.

\section{REFERENCES}

1. Desai P, Himel V. Comparative safety of various intracanal irrigation systems. J Endod. 2009;35:545-9.

2. van der Sluis LW, Gambarini G, Wu MK, Wesselink PR. The influence of volume, type of irrigant and flushing method on removing artificially placed dentine debris from the apical root canal during passive ultrasonic irrigation. Int Endod J. 2006;39:472-6.

3. Uroz-Torres D, Gonzalez-Rodriguez MP, Ferrer-Luque CM. Effectiveness of the EndoActivator System in removing the smear layer after root canal instrumentation. J Endod. 2010;36:308-11.

4. Ruddle CJ. Hydrodynamic disinfection: tsunami endodontics. Dent Today. 2007;26:110, 112, 114-7.

5. Akman M, Akbulut MB, Aydinbelge HA, Belli S. Comparison of different irrigation activation regimens and conventional irrigation techniques for the removal of modified triple antibiotic paste from root canals. J Endod. 2015;41:720-4.

6. Stamos DE, Sadeghi EM, Haasch GC, Gerstein H. An in vitro comparison study to quantitate the debridement ability of hand, sonic, and ultrasonic instrumentation. J Endod. 1987;13:43440.

7. Sabins RA, Johnson JD, Hellstein JW. A comparison of the cleaning efficacy of short-term sonic and ultrasonic passive irrigation after hand instrumentation in molar root canals. J Endod. 2003;29:674-8.

8. Kato AS, Cunha RS, da Silveira Bueno CE, Pelegrine RA, Fontana CE, de Martin AS. Investigation of the efficacy of passive ultrasonic irrigation versus irrigation with reciprocating activation: An environmental scanning electron microscopic study. J Endod. 2016;42: 659-63.

9. Schneider SW. A comparison of canal preparations in straight and curved root canals. Oral Surg Oral Med Oral Pathol. 1971;32:271-5.
10. Sydney GB, Batista A, de Melo LL. The radiographic platform: a new method to evaluate root canal preparation in vitro. J Endod. 1991;17:570-2.

11. Mitchell RP, Yang SE, Baumgartner JC. Comparison of apical extrusion of $\mathrm{NaOCl}$ using the EndoVac or needle irrigation of root canals. J Endod. 2010;36:338-41.

12. Guastalli AR, Clarkson RM, Rossi-Fedele G. The Effect of Surfactants on the Stability of Sodium Hypochlorite Preparations. J Endod. 2015;41:1344-8.

13. Gopikrishna V, Ashok P, Kumar AP, Narayanan LL. Influence of temperature and concentration on the dynamic viscosity of sodium hypochlorite in comparison with $17 \%$ EDTA and 2\% chlorhexidine gluconate: An in vitro study. J Conserv Dent. 2014; 17:57-60.

14. Seeliger E, Lenhard DC, Persson PB. Contrast media viscosity versus osmolality in kidney injury: lessons from animal studies. Biomed Res Int. 2014;2014:358136.

15. Bronnec F, Bouillaguet S, Machtou P. Ex vivo assessment of irrigant penetration and renewal during the final irrigation regimen. Int Endod J. 2010;43:663-72.

16. Lee SJ, Wu MK, Wesselink PR. The effectiveness of syringe irrigation and ultrasonics to remove debris from simulated irregularities within prepared root canal walls. Int Endod J. 2004;37:672-8.

17. Shin SJ, Kim HK, Jung IY, Lee CY, Lee SJ, Kim E. Comparison of the cleaning efficacy of a new apical negative pressure irrigating system with conventional irrigation needles in the root canals. Oral Surg Oral Med Oral Pathol Oral Radiol Endod. 2010;109:479-84.

18. Tay FR, Gu LS, Schoeffel GJ, Wimmer C, Susin L, Zhang $\mathrm{K}$, et al. Effect of vapor lock on root canal debridement by using a side-vented needle for positive-pressure irrigant delivery. J Endod. 2010;36:745-50.

19. Cameron JA. The synergistic relationship between ultrasound and sodium hypochlorite: a scanning electron microscope evaluation. J Endod. 1987;13:541-5.

20. Rodig T, Dollmann S, Konietschke F, Drebenstedt S, Hulsmann M. Effectiveness of different irrigant agitation techniques on debris and smear layer removal in curved root canals: a scanning electron microscopy study. J Endod. 2010;36:1983-7.

21. Huffaker SK, Safavi K, Spangberg LS, Kaufman B. Influence of a passive sonic irrigation system on the elimination of bacteria from root canal systems: a clinical study. J Endod. 2010;36:1315-8.

22. Barnett F, Trope M, Khoja M, Tronstad L. Bacteriologic status of the root canal after sonic, ultrasonic and hand instrumentation. Endod Dent Traumatol. 1985;1:228-31.

23. Reynolds MA, Madison S, Walton RE, Krell KV, Rittman BR. An in vitro histological comparison of the step-back, sonic, and ultrasonic instrumentation techniques in small, curved root canals. J Endod. 1987; 13:307-14. 